\title{
Prevalence and patterns of traumatic dental injuries in primary teeth: a 3-year retrospective overview study in Vienna
}

\author{
Sophie Lembacher ${ }^{1} \cdot$ Steffen Schneider ${ }^{2} \cdot$ Steffen Lettner $^{3} \cdot$ Katrin Bekes $^{1}$ (D)
}

Received: 29 June 2021 / Accepted: 21 September 2021 / Published online: 6 November 2021

(c) The Author(s) 2021, corrected publication 2022

\begin{abstract}
Objectives The aim of this study was to retrospectively identify the prevalence, patterns, and accident types of traumatic dental injuries (TDIs) in children with primary teeth in Vienna, Austria.

Material and methods The investigation was conducted as a retrospective overview study including all children with TDIs in primary teeth at the University Dental Clinic of Vienna (Austria) between 2014 and 2016. Dental records including age, gender, location of trauma, type of trauma, cause of TDI, and location of traumatic incident were obtained. Furthermore, the time of presentation and the time span between TDI and initial treatment were evaluated.

Results The sample comprised TDIs in 243 patients with 403 primary teeth. In a ratio of 1:1.45, boys were significantly more involved than girls. Upper central and lateral incisors were most frequently affected $(n=371,92.1 \%)$. Dislocations were the most common type of injury $(n=298,74 \%)$ with subluxations being the most prevalent form $(n=85,28.5 \%)$. In $23 \%(n=92)$, fractures were observed. The majority of traumatic incidents occurred at home $(88.5 \%)$.

Conclusion The injury characteristics are comparable to what has previously been reported in other studies in pediatric populations.

Clinical relevance TDIs are a prevalent event in children worldwide and incisors are the most affected teeth in the primary dentition. Thus, dental practitioners should be able to handle these injuries.
\end{abstract}

Keywords Traumatic dental injuries $\cdot$ Primary dentition $\cdot$ Incidence $\cdot$ Tooth fracture $\cdot$ Dislocation $\cdot$ Austria

\section{Introduction}

Traumatic dental injuries (TDIs) are one of the most serious dental public health problems among the younger population as most injuries occur in childhood or adolescence. For children aged 0 to 6 years, oral injuries account for as much as $17 \%$ of all bodily injuries [1]. Approximately onethird of toddlers and preschool children suffer dental trauma

Katrin Bekes

katrin.bekes@meduniwien.ac.at

1 Medical University of Vienna, University Clinic of Dentistry, Department of Paediatric Dentistry, Sensengasse 2a, Vienna 1090, Austria

2 Medical University of Vienna, Department of Oral and Maxillofacial Surgery, Spitalgasse 23, Vienna 1090, Austria

3 Medical University of Vienna, Karl Donath Laboratory for Hard Tissue and Biomaterial Research, Statistics, School of Dentistry, Sensengasse 2a, Vienna 1090, Austria involving the primary dentition. In many cases, a dental traumatic injury in deciduous teeth is the reason for the child's first visit to the dentist [2,3]. A structured approach to minimize anxiety and provide immediate care is essential and poses a challenge to parents as well as clinicians in pediatric dentistry. But TDIs do not only cause painful and distressing events. They also may have aesthetic, functional, economic, and psychosocial effects [4-6]. In addition to immediately measurable clinical consequences, potential sequelae to developing succedaneous permanent teeth including hypoplasia, root dilacerations, and other enamel or development disturbances present lasting complications [7-9]. Furthermore, TDIs in deciduous teeth increase the risk for dental trauma in the permanent dentition [10]. This highlights the impact that TDIs in primary teeth have on public health. The prognosis of traumatized teeth is equally dependent on the quality of immediate emergency care at the time and place of traumatic incident and initial professional medical assessment and treatment $[1,11]$. Several publications have discussed dental trauma in the primary 
and permanent dentition. The global prevalence of TDIs in primary teeth ranges between 11 and $47 \%$ [1, 2, 12]. The International Association of Dental Traumatology estimates the prevalence at $22.7 \%[3,13]$. The considerable variability in reported prevalence of TDIs likely derives from incoherence in applied trauma classification systems, geographical, socioeconomic, and behavioral differences between study locations and countries [14]. Considering that many apparently minor injuries remain unreported, the number of TDIs is likely to be underestimated [2]. The Department of Emergency Dental Care at the University Dental Clinic in Vienna is the only specialized unit for TDIs in the area within the public university system. In view of 944 local dentist offices, two additional hospitals with dental-care units, and 18 outpatient clinics, the tendency for a decentralized approach in regard to provision for dental care in Vienna, a city with 1.87 million inhabitants, is apparent.

However, so far there has only been little epidemiological research in dental traumatology in Austria. Existing epidemiologic data primarily focuses on dental trauma in the context of facial injuries or is based on selective patient cohorts limited to different injury or accident types in permanent teeth $[15,16]$. Therefore, the aim of the present retrospective study was to evaluate TDIs in primary teeth in Vienna between 2014 and 2016. Several variables relating to TDIs were analyzed including gender, type of injury, number of affected teeth, location of traumatic incident, and causes of TDIs.

\section{Material and methods}

The study was conducted as a retrospective overview study including all children with a TDI in the primary dentition who presented at the Department of Emergency Dental Care at the University Dental Clinic in Vienna (Austria) between
January 2014 and December 2016. Medical records were retrieved from the electronic patient registry. The data provided was registered by 26 practitioners of varying backgrounds in regard to their specialization during their routine shifts at the Department of Emergency Dental Care. 64.2\% $(n=156)$ of patients were registered by permanent residents of the Emergency Care Unit, $16 \%(n=39)$ by pediatric dentists, and $19.8 \%(n=48)$ by practitioners of varying other specializations (e.g., oral surgeons, endodontists, prosthodontists). All TDIs affecting primary teeth were considered for inclusion in the study. Exclusion criteria comprised injuries to permanent teeth or deficient records. Relevant data were classified and grouped according to age, gender, the time interval between trauma and arrival at the clinic, affected teeth, type of trauma, etiology of TDI, and location of traumatic incident. The classification of dental trauma was conducted in accordance with the classification system of the World Health Organization which was slightly modified by Andreasen et al. [8]. Hence, TDIs were classified into injuries to the dental hard tissues and pulp (enamel infraction, crown fracture without pulp exposure (uncomplicated crown fracture), crown fracture with pulp exposure (complicated crown fracture), crown-root fracture, root fracture) and injuries to the periodontal tissue (concussion, subluxation, lateral dislocation, intrusion, extrusion, and avulsion) (Table 1). Additionally, combined injuries were introduced as a third diagnostic entity which were defined as simultaneously occurring fractures and dislocations within the same tooth at the same time (meaning per trauma). Table 1 presents the three main categories of dental trauma and their subgroups observed in this study. Clinical oral and radiographic examinations were conducted in accordance with current guidelines of the German Society of Dental, Oral and Craniomandibular Sciences (DGZMK) [17]. Exceptions for radiographic diagnostics were only made if the patient was not compliant.
Table 1 Classification of dental trauma used in the present study [8]

\begin{tabular}{ll}
\hline Type of trauma & Abbreviation \\
\hline Fracture & F \\
Enamel infraction & EF \\
Crown fracture & CFP \\
With pulp exposure & CFX \\
No pulp exposure & CRF \\
Crown-root fracture & RF \\
Root fracture & D \\
Dislocation & CCS \\
Concussion & LOS \\
Subluxation & LDL \\
Lateral dislocation & INT \\
Intrusion & EXT \\
Extrusion & AVU \\
Avulsion & C \\
Combined injuries & \\
Fractures and dislocations simultaneously occurring within the same tooth at the same time & \\
\hline
\end{tabular}


Fig. 1 Age distribution of patients with regard to gender
A

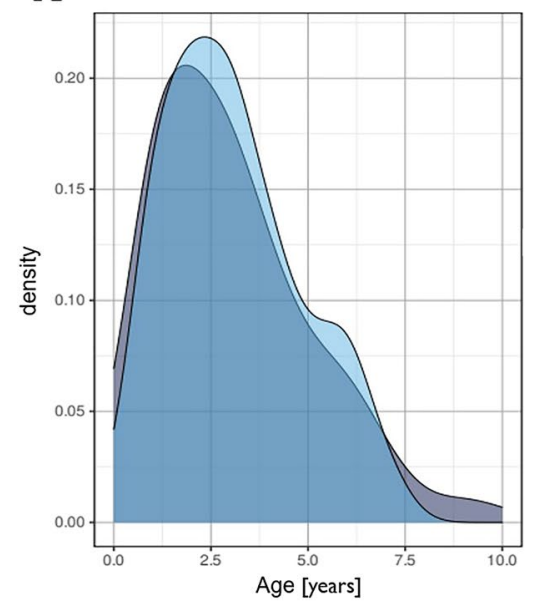

B

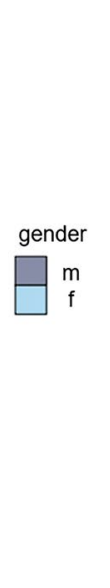

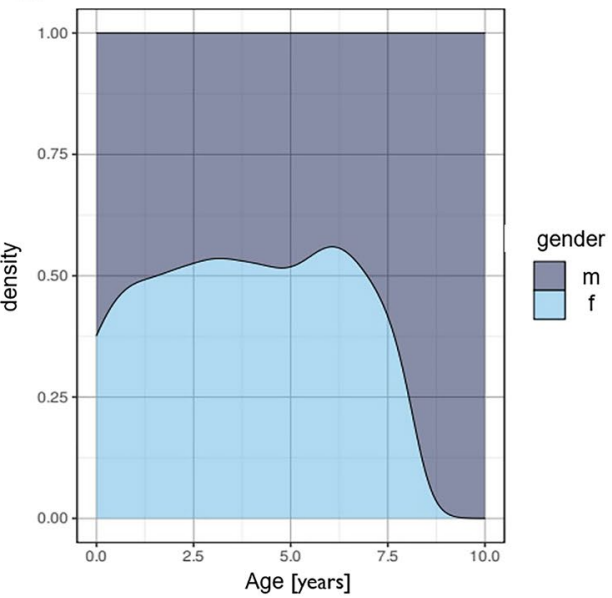

Statistical analysis was performed with $\mathrm{R}$ version 4.0.2 (R Core Team 2020, Austria). Descriptive statistics (mean, $\mathrm{SD}$ ) were provided for continuous measurements (time to treatment, age). Nominal measurements (e.g., gender, type of injury, type of accident) are summarized using frequencies and proportions as well as crosstabulations. Wilson score intervals and $\chi^{2}$ tests with continuity correction were calculated to compare interesting proportions. For visualization kernel density estimators (KDE), a continuous version of histograms was used. Graphs were created using MS Excel $^{\mathrm{TM}} 2016$ (IBM, USA).

\section{Results}

The sample comprised 403 deciduous teeth of 243 patients with TDIs in the primary dentition. At the time of injury, the mean age was 3.08 years ( \pm 1.9 , range $0-10$ years). A peak was observed between the first and second year of life (Fig. 1). With a gender ratio of 1:1.45, 59.3\% (95\% CI: $52.8-65.4 \%, n=144$ ) of the patients were males and $40.7 \%$ (95\% CI: $34.6-47.2 \%, n=99)$ females. With a $\chi^{2}$ test with Yates' continuity correction calculating a $p$-value of 0.0048 , boys were significantly more affected by TDIs than girls.

In $77 \%(n=187)$ of cases, patients $(n=187)$ immediately sought emergency care at the Department of Emergency Dental Care at the University Dental Clinic of Vienna, whereas $11.4 \%(n=28)$ were referrals. One patient was referred by a general practitioner, one by a pediatrician and 10 patients by dentists. Sixteen patients sought immediate care after having been referred by emergency hospitals. For 28 patients, no information was available. The majority of patients presented during official clinic hours on weekdays, the busiest day being Friday $(n=41)$ (Table 2). Out of 220 accidents, 68 occurred on holidays or weekends. Figure 2 shows the relative likelihood of a TDI per date in a kernel density estimation (KDE) plot. The horizontal line shows average relative likelihood for comparison. From early November to the end of May, there were relatively fewer TDIs. A relatively higher amount of TDIs was observed from May to the beginning of November. With regard to clinic arrival time following dental trauma, $65.2 \%(n=144)$ sought treatment within the first $24 \mathrm{~h}$ after TDI with a maximum at $2 \mathrm{~h}$. Figure 3 shows the average time passed until treatment.

Ninety-eight percent $(n=241)$ of cases presented with first-time dental trauma, whereas $2 \%(n=5)$ had previously suffered from TDIs. Accompanying soft tissue injuries (laceration, abrasion, etc.) were present in 95 (39.1\%) patients. In $52 \%(n=127)$ of cases, only one deciduous tooth was affected. Twenty-nine percent $(n=72)$ showed two traumatized teeth within the same incident. The distribution of the number of affected teeth per traumatic incident is listed in Table 3 in relation to gender. Figure 4 shows the distribution of TDIs regarding tooth identification number and gender. Maxillary teeth were involved significantly more often $(n=229,93.1 \%)$. Upper central incisors were found to be the most frequently affected by dental trauma ( $n=296,73.5 \%)$, followed by upper lateral incisors $(n=75,18.6 \%)$. In $4.5 \%(n=11)$ of cases, TDI occurred in teeth in the lower jaw and in $2.4 \%(n=6)$ in the upper and lower jaw at the same time. In 97\% $(n=391)$,

Table 2 Frequency of TDI occurrence per weekday

\begin{tabular}{ll}
\hline Day of the week & $n$ \\
\hline Monday & 31 \\
Tuesday & 26 \\
Wednesday & 24 \\
Thursday & 34 \\
Friday & 41 \\
Saturday & 30 \\
Sunday & 34 \\
\hline
\end{tabular}


Fig. 2 Kernel density estimation (KDE) plot for the relative likelihood of a TDI per date

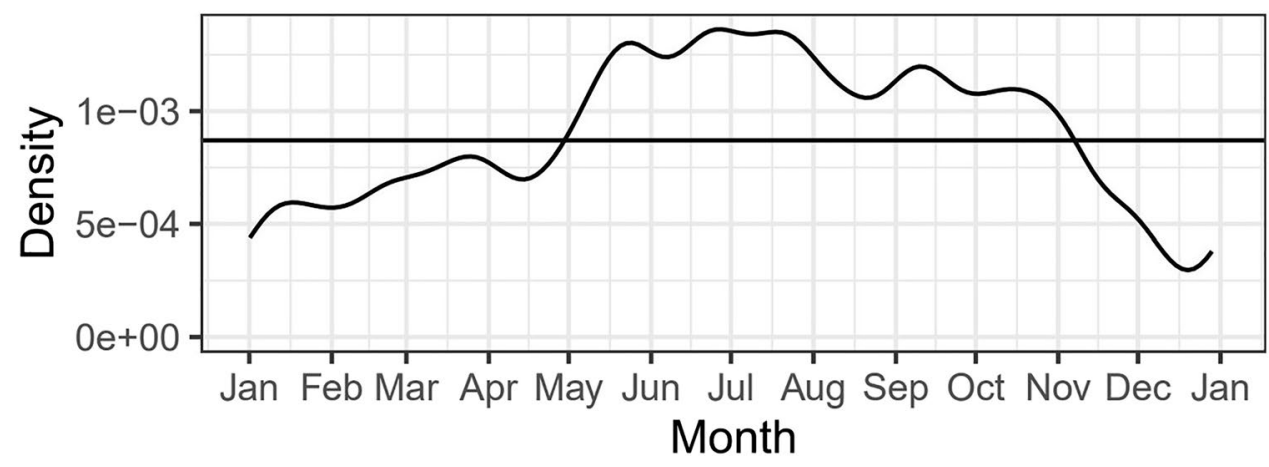

Fig. 3 Time to treatment a single injury type was diagnosed, the majority being dislocations $(n=298,74 \%)$. The most common type of dislocations was subluxation $(n=85,28.5 \%)$, followed by lateral dislocation $(n=61,20.5 \%)$ and intrusion $(n=52$, $17.4 \%)$. Forty-three patients suffered from avulsions $(14.4 \%)$. Twenty-three percent $(n=92)$ of injuries were classified as fractures. In $3 \%(n=12)$ of patients, both periodontal und hard dental tissue injuries were present with the most frequent combined injury being crown fractures along with increased tooth mobility $(n=4)$ The distribution of fractures, dislocations, and combined injuries is shown in Table 4 . Table 5 presents an incidence matrix that gives thorough insight into how many times what type of TDI occurred. It also includes all possible variations of combined injury types. For example, 56 patients suffered from intrusions. In 54 out of these 56 intrusion cases, no other injury was observed. In 2 cases, however, the intrusion occurred in combination with crown fractures.

In analyzing different causes of TDI, falling accidents proved to be the most prevalent reason in dental trauma in primary teeth $(86 \%, n=209$; male: $n=124,86.1 \%$; female: $n=80,85.9 \%)$. Only 6 males $(4.2 \%)$ and 3 females $(3.0 \%)$ suffered dental trauma through punching. In $3.5 \%$ of males $(n=5)$ and $3.0 \%$ of females $(n=3)$, dental trauma occurred due to collision accidents (Table 6). The correlation between accident and injury types established by crosstabulations shows that punching mostly caused dislocations $(n=15$,
$93.8 \%$ ). The number of fractures and combined injuries increased due to falling or collision accidents. In $88.5 \%$ $(n=215)$ of cases, the traumatic incident occurred at home. TDIs due to accidents at preschools or schools were identified in $3.7 \%(n=9)$ of cases. Accidents during leisure activities were observed in $2.5 \%(n=6)$ and in traffic in $1.6 \%$ $(n=4)$.

\section{Discussion}

Traumatic dental injuries present a challenging health problem in many societies, especially in children. However, in the literature, only few reports address TDIs to the primary dentition. The risk for dental trauma in deciduous teeth is especially high between the ages of 2 and 3 years old. During this time period, motor coordination is developing and children of both genders are learning to walk [14]. Hence, the risk for falling accidents increases. The presented analysis of etiology of dental trauma showed that falling accidents were determined as the main cause of TDIs (male: $n=118$, $86 \%$; female: $n=80,85 \%$ ). With falling being the predominant cause of TDIs, the frequency of TDI occurrence on weekdays and on weekends is expected to be similar in young patients. The presented data confirms this assumption as the frequencies of TDI occurrence only show minimal variations in regard to the day of week. As other recent 
Table 3 Number of injured primary teeth per trauma and gender

\begin{tabular}{|c|c|c|c|c|c|c|c|c|c|c|}
\hline & \multicolumn{10}{|c|}{ Number of injured primary teeth } \\
\hline & \multicolumn{2}{|l|}{1} & \multicolumn{2}{|l|}{2} & \multicolumn{2}{|l|}{3} & \multicolumn{2}{|l|}{4} & \multicolumn{2}{|l|}{5} \\
\hline & $n$ & $\%$ & $n$ & $\%$ & $n$ & $\%$ & $n$ & $\%$ & $n$ & $\%$ \\
\hline All & 127 & 52 & 72 & 29 & 31 & 13 & 13 & 5 & 3 & 1 \\
\hline Male & 79 & 54 & 41 & 28 & 18 & 12 & 6 & 4 & 2 & 1 \\
\hline Female & 48 & 48 & 31 & 31 & 13 & 13 & 7 & 7 & 1 & 1 \\
\hline
\end{tabular}

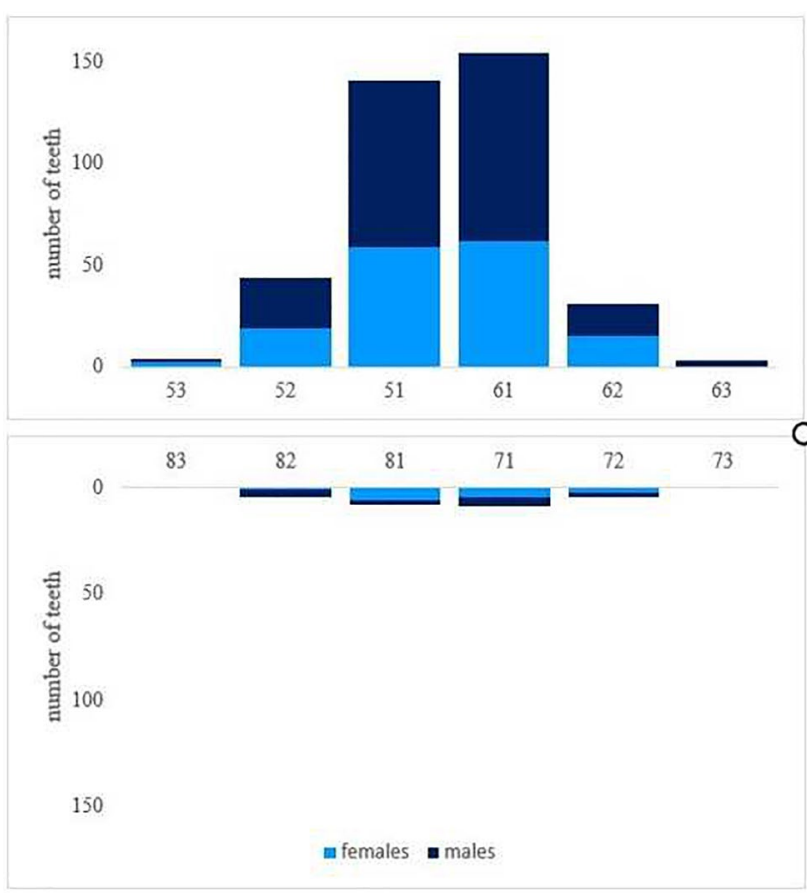

Fig. 4 Distribution of traumatized teeth type per gender

studies have shown similar results, the relative likelihood of a TDI occurrence being higher from May to November may be linked to the fact that outdoor activities entailing higher risks of falling accidents increase in spring and summer [18, 19]. Oldin et al. [20] showed that the frequencies of different causes for TDI vary with age. In older children and adolescents with permanent teeth, falling remains the dominant cause for TDIs. However, falling accidents are now primarily linked to sports and behavioral factors [20]. It was observed that boys are more prone to risky and aggressive behavior than girls. Yet, more recent studies have proven that the prevalence in male and female patients is equalizing in older children as girls are developing similar athletic interests and are exposed to the same risk factors in western countries as boys $[3,21]$. In the presented study, the prevalence of dental trauma in deciduous teeth was significantly higher in boys compared to girls ( $\mathrm{m}: \mathrm{f}=1: 1.45, p=0.048$ ). This correlates with demographic evaluations of previous literature $[18,22]$. Compared to gender ratio of TDIs in the
Table 4 Distribution of injury type

\begin{tabular}{llll}
\hline Type of trauma & Classification & $n$ & $\%$ \\
\hline Fracture & & 92 & 23.0 \\
& EF & 1 & 1.1 \\
& CF & 48 & 52.2 \\
& CFP & 18 & 19.6 \\
& CRF & 19 & 20.7 \\
Dislocation & RF & 3 & 3.3 \\
& & 298 & 74.0 \\
& CCS & 33 & 11.1 \\
& LOS & 85 & 28.5 \\
& LDL & 61 & 20.5 \\
& INT & 52 & 17.4 \\
& EXT & 21 & 7.0 \\
Combined injury & AVU & 43 & 14.4 \\
& & 12 & 3.0 \\
& EF & 3 & 25.0 \\
& CF & 8 & 66.7 \\
& CFP & 1 & 8.3 \\
& LOS & 7 & 58.3 \\
& LDL & 3 & 25.0 \\
& INT & 2 & 16.7 \\
\hline
\end{tabular}

permanent dentition, however, the difference between male and female patients is less prominent [14]. This difference may be attributed to varying etiologic factors within different age groups. Further, the relative share of TDIs in regard to gender shows no significant difference from the ages of 0 to 7 years old. From the ages of 8 to 10 years old, however, only boys were affected by TDIs in primary teeth. Multiple studies have confirmed that the eruption times of permanent teeth are earlier in females than males [23-25]. Hence, it is possible that the chance of TDIs in primary teeth at the ages of 8 to 10 years old is consequently lower in girls due to already erupting permanent teeth. In regard to the different accident types, boys prove to be the dominant gender in all categories. Interestingly, the gender gap narrows the more teeth are affected in one incident. TDIs affecting one, two, or three teeth occurred more often in boys. However, TDIs including four teeth were observed more often in girls than boys (m: $n=6$, f: $n=7$ ). 
Table 5 Incidence matrix for TDI

Table 6 Accident and injury types of TDI

\begin{tabular}{llllllllllll}
\hline & EF & CF & CFP & CRF & RF & CCS & LOS & LDL & INT & EXT & AVU \\
\hline EF & 4 & 0 & 0 & 0 & 0 & 0 & 3 & 0 & 0 & 0 & 0 \\
CF & 0 & 56 & 0 & 0 & 0 & 0 & 4 & 2 & 2 & 0 & 0 \\
CFP & 0 & 0 & 19 & 0 & 0 & 0 & 0 & 1 & 0 & 0 & 0 \\
CRF & 0 & 0 & 0 & 19 & 0 & 0 & 0 & 0 & 0 & 0 & 0 \\
RF & 0 & 0 & 0 & 0 & 3 & 0 & 0 & 0 & 0 & 0 & 0 \\
CCS & 0 & 0 & 0 & 0 & 0 & 33 & 0 & 0 & 0 & 0 & 0 \\
LOS & 3 & 4 & 0 & 0 & 0 & 0 & 92 & 0 & 0 & 0 & 0 \\
LDL & 0 & 2 & 1 & 0 & 0 & 0 & 0 & 64 & 0 & 0 & 0 \\
INT & 0 & 2 & 0 & 0 & 0 & 0 & 0 & 0 & 54 & 0 & 0 \\
EXT & 0 & 0 & 0 & 0 & 0 & 0 & 0 & 0 & 0 & 24 & 0 \\
AVU & 0 & 0 & 0 & 0 & 0 & 0 & 0 & 0 & 0 & 0 & 43 \\
\hline
\end{tabular}

\begin{tabular}{|c|c|c|c|c|c|c|c|c|c|c|c|c|}
\hline \multirow[t]{3}{*}{ Accident type } & \multicolumn{6}{|c|}{ Gender } & \multicolumn{6}{|c|}{ Injury type } \\
\hline & Total & & Male & & Female & & D & & $\mathbf{F}$ & & $\mathbf{C}$ & \\
\hline & $n$ & $\%$ & $n$ & $\%$ & $n$ & $\%$ & $n$ & $\%$ & $n$ & $\%$ & $n$ & $\%$ \\
\hline Punching & 9 & 3.7 & 6 & 4.2 & 3 & 3.0 & 15 & 93.8 & 1 & 6.2 & 0 & 0.0 \\
\hline Falling & 209 & 86.0 & 124 & 86.1 & 85 & 85.9 & 260 & 73.9 & 80 & 22.7 & 3.1 & 0 \\
\hline Collision accidents & 8 & 3.3 & 5 & 3.5 & 3 & 3.0 & 10 & 83.3 & 2 & 16.7 & 0 & 0.0 \\
\hline Not known & 17 & 7.0 & 9 & 6.2 & 8 & 8.1 & 13 & 56.5 & 9 & 39.1 & 1 & 4.3 \\
\hline
\end{tabular}

Most patients initially sought initial treatment at the Department of Emergency Dental Care at the University Dental Clinic of Vienna $(n=187,77 \%)$ during clinic hours on weekdays. Only $11.4 \%(n=28)$ presented as referrals. This confirms a rather high awareness level of the parents of the presented patient collective to consult specialized dental departments rather than common emergency departments in children's hospitals for TDIs. Almost two-thirds of patients ( $n=144,65.2 \%$ ) arrived within the first $24 \mathrm{~h}$ after TDI at the clinic. After 1 week, $89.1 \%$ of patients with TDIs $(n=197)$ had presented at the clinic. Reports have suggested that the most common reasons for considerable time lapses in some cases are underestimation of TDIs and its potential complications in the primary dentition. Prolonged transit time or parental unavailability also played into late arrival times [26, 27]. This emphasizes the importance of decentral dental care units within appropriate distance. As TDIs fairly evenly occur on weekdays as well as on weekends, opening hours of these support units should be extended to weekends.

Evaluating the pattern of affected teeth, the results show that upper central incisors were the most frequently injured teeth $(73.5 \%)$. This is coherent with international data [1, $18,28]$. With $83.3 \%$, De Amorim et al. observed a slightly higher value in a specialized pediatric practice in Brasil from 1993 to 2008 [29]. Due to their anterior position, upper incisors are more prone to be affected in traumatic incidents. Additional risk factors include insufficient lip closure, an overjet over $3 \mathrm{~mm}$, and protrusion of upper anterior teeth
[22, 30-32]. Overbite and canine classification have also been linked to higher incidence of TDI in deciduous teeth [22, 30, 33]. In contrast, lower incisors are more likely to be protected from TDI by lower lip and upper incisors. In this study in only $4.7 \%$, TDIs occurred in lower teeth.

Based on the analysis of the presented data, dislocations were more prevalent than fractures or combined injuries. This confirms international trends of dislocations being the most common injury type in deciduous teeth due to the elasticity of alveolar bone and lower crown-root-relation at a younger age $[14,18]$. With $74 \%$ of TDIs being dislocations, the percentage is slightly higher compared to the results of a recently published data report by Agouropoulos et al. who observed luxation injuries in $69 \%$ of cases in the primary dentition [18]. In the presented study, subluxations were the most frequent subtype of dislocation injuries (28.5\%). This compared well to the results of De Amorim et al. (35.1\%) [29]. Yet, the presented result is lower to previous findings of Mendoza-Mendoza et al. [34] in a retrospective cohort study on Spanish children between 0 and 7 years old (47.29\%). At the same time, $17.4 \%$ intrusions and $14.4 \%$ avulsions compare well to Mendoza-Mendoza's results in 2015 (intrusions: $23.15 \%$, avulsions: $13.63 \%$ ) [34]. Due to varying classification systems, however, the grounds for comparing incidence and prevalence in reference to different injury types and their subgroups with other notable studies are limited [35].

In addition, the findings of this study reveal that in $88.3 \%$ of cases the traumatic incident occurred at home. This is 
consistent with the results of a literature review that identified accidents within and around the home as the major source of TDI in deciduous teeth [14]. Other studies show that the main occurrence of TDIs is at home $(43.5 \%)$, followed by traumatic incidents at school (10.1\%) [29]. With $3.9 \%$, the findings of this study, however, reveal a lower rate of TDI occurrence at school. Accidents during leisure activities including sports were observed in $2.6 \%$ of cases. Therefore, educational campaigns about the risk of dental trauma and prevention methods in order to increase health awareness and anticipatory guidance for families and teachers should be advised. Besides the previously mentioned oral predisposing factors, individual behavioral characteristics play an essential role in risk evaluation. To reduce the risk and incidence of dental trauma during sports, the use of protective athletic appliances such as mouth guards is considered an important preventative measure in older children and adolescents [36, 37]. Yet the motivation and compliance of younger children to wear such an appliance need to be further examined as they might present as a veritable limitation. Additionally, concerns in regard to their necessary regular renewal due to growth and development with age need to be considered in a thorough risk-benefit analysis before endorsing mouth guards for smaller children in clinical practice. The fact that only $1.3 \%(n=3)$ of TDIs were caused in traffic can most likely be explained with the age groups represented in this study. A study has shown that dental trauma resulting from traffic accidents occurs most often in the second and third life decades [15].

This study's findings should be framed by acknowledging its limitations. The analysis performed included a cohort of 243 patients that presented during opening hours on weekdays and on weekends at the Department of Emergency Dental Care at the University Dental Clinic in Vienna. Dental trauma that presented with local dentists or other emergency units was not taken into account. To gain a more comprehensive overview for Vienna, a multicenter approach including local dental offices is necessary. Furthermore, treatment outcomes were not evaluated in the presented study. It must also be acknowledged that due to varying classification systems the comparison of prevalence in reference to different injury types with other notable studies was difficult to assess. Combined injuries are often not examined as a separate entity. This underlines the importance of epidemiology and the study of patterns and causes of TDIs at a national and international population level on the basis of a standardized approach to reporting, classification, and methodology. Hence, a multicenter approach with the implantation of standardized classification protocols is recommended in order to gain a more comprehensive analysis of incidence, prevalence, and patterns of TDIs in deciduous teeth in Austria; develop national references; and explore regional differences. Standardized documentation in conjunction with the installation of prospective databases for initial assessment, treatment, and follow-up of treatment outcome is strongly recommended.

\section{Conclusion}

The presented study is the first research on dental trauma in primary teeth in Austria. By large, the results correlate with previously published international data. Due to the high prevalence of TDIs in children, dental injuries present a frequent occurrence in daily practice worldwide. As their accurate treatment often proves to be a challenge to dentists in their daily practice, further education and training of dentists in the field of dental traumatology is strongly advised. The establishment of a regional network of trained dentists would be favorable. In this regard, online introductions such as the dental trauma guide can be useful tools. Furthermore, the city's approach of decentralized care structures should be continued and the installation of more decentral support units and immediate dental care facilities within appropriate distance offering standardized documentation and treatment protocols should be encouraged.

Author contribution Conceived and designed the study: SS, KB.

Conducted the study: SS, KB.

Analyzed the data: SS, StL, KB.

Interpreted the data: All authors.

Wrote the manuscript: SL, KB.

Read, revised, and agreed to be accountable for the manuscript: All authors.

Funding Open access funding provided by Medical University of Vienna. The study was funded by $3 \mathrm{M}$.

\section{Declarations}

Ethical approval All procedures performed in studies involving human participants were in accordance with the ethical standards of the institutional and/or national research committee and with the 1964 Helsinki declaration and its later amendments or comparable ethical standards.

This article does not contain any studies with animals performed by any of the authors.

Informed consent Informed consent was obtained from all individual participants included in the study.

Conflict of interest The authors declare no competing interests.

Open Access This article is licensed under a Creative Commons Attribution 4.0 International License, which permits use, sharing, adaptation, distribution and reproduction in any medium or format, as long as you give appropriate credit to the original author(s) and the source, provide a link to the Creative Commons licence, and indicate if changes were made. The images or other third party material in this article are included in the article's Creative Commons licence, unless indicated 
otherwise in a credit line to the material. If material is not included in the article's Creative Commons licence and your intended use is not permitted by statutory regulation or exceeds the permitted use, you will need to obtain permission directly from the copyright holder. To view a copy of this licence, visit http://creativecommons.org/licenses/by/4.0/.

\section{References}

1. Andersson L (2013) Epidemiology of traumatic dental injuries. Pediatr Dent 35:102-105

2. Lam R (2016) Epidemiology and outcomes of traumatic dental injuries: a review of the literature. Aust Dent J 61(Suppl 1):4-20. https://doi.org/10.1111/adj.12395

3. Glendor U (2008) Epidemiology of traumatic dental injuries-a 12 year review of the literature. Dent Traumatol 24:603-611. https:// doi.org/10.1111/j.1600-9657.2008.00696.x

4. Bani M, Alacam A, Cinar C (2017) How does dental trauma affect the quality of life in Turkish families? Oral Health Prev Dent 15:563-567. https://doi.org/10.3290/j.ohpd.a38573

5. Borum MK, Andreasen JO (2001) Therapeutic and economic implications of traumatic dental injuries in Denmark: an estimate based on 7549 patients treated at a major trauma centre. Int $\mathrm{J}$ Paediatr Dent 11:249-258. https://doi.org/10.1046/j.1365-263x. 2001.00277.x

6. Lee JY, Divaris K (2009) Hidden consequences of dental trauma: the social and psychological effects. Pediatr Dent 31:96-101

7. Lenzi MM, Alexandria AK, Ferreira DM, Maia LC (2015) Does trauma in the primary dentition cause sequelae in permanent successors? A systematic review. Dent Traumatol 31:79-88. https:// doi.org/10.1111/edt.12149

8. Andreasen JO, Andreasen FM, Andersson L (2018) Textbook and color atlas of traumatic injuries to the teeth, 5th edn. WileyBlackwell, Oxford

9. de Amorim LF, Estrela C, da Costa LR (2011) Effects of traumatic dental injuries to primary teeth on permanent teeth-a clinical follow-up study. Dent Traumatol 27:117-121. https://doi.org/ 10.1111/j.1600-9657.2010.00959.x

10. Goettems ML, Brancher LC, da Costa CT, Bonow MLM, Romano AR (2017) Does dental trauma in the primary dentition increases the likelihood of trauma in the permanent dentition? A longitudinal study. Clin Oral Investig 21:2415-2420. https://doi.org/10. 1007/s00784-016-2037-3

11. Zaleckiene V, Peciuliene V, Brukiene V, Drukteinis S (2014) Traumatic dental injuries: etiology, prevalence and possible outcomes. Stomatologija 16:7-14

12. Granville-Garcia AF, Vieira IT, Siqueira MJ, de Menezes VA, Cavalcanti AL (2010) Traumatic dental injuries and associated factors among Brazilian preschool children aged 1-5 years. Acta Odontol Latinoam 23:47-52

13. Day PF, Flores MT, O'Connell AC, Abbott PV, Tsilingaridis G, Fouad AF, Cohenca N, Lauridsen E, Bourguignon C, Hicks L, Andreasen JO, Cehreli ZC, Harlamb S, Kahler B, Oginni A, Semper M, Levin L (2020) International Association of Dental Traumatology guidelines for the management of traumatic dental injuries: 3 . Injuries in the primary dentition. Dent Traumatol 36:343-359. https://doi.org/10.1111/edt.12576

14. Bastone EB, Freer TJ, McNamara JR (2000) Epidemiology of dental trauma: a review of the literature. Aust Dent J 45:2-9. https:// doi.org/10.1111/j.1834-7819.2000.tb00234.x

15. Gassner R, Bosch R, Tuli T, Emshoff R (1999) Prevalence of dental trauma in 6000 patients with facial injuries: implications for prevention. Oral Surg Oral Med Oral Pathol Oral Radiol Endod 87:27-33. https://doi.org/10.1016/s1079-2104(99)70290-8
16. Lechner K, Connert T, Kuhl S, Filippi A (2017) Lip and tooth injuries at public swimming pools in Austria. Dent Traumatol 33:214-220. https://doi.org/10.1111/edt.12331

17. Deutsche Gesellschaft für Zahn- M-uK S2k-Leitlinie: Therapie des dentalen Traumas bleibender Zähne, AWMF-Registernummer 083-004.

18. Agouropoulos A, Pavlou N, Kotsanti M, Gourtsogianni S, Tzanetakis G, Gizani S (2021) A 5-year data report of traumatic dental injuries in children and adolescents from a major dental trauma center in Greece. Dent Traumatol 37:631-638. https://doi.org/10. 1111/edt.12678

19. Alhaddad B, Rozsa NK, Tarjan I (2019) Dental trauma in children in Budapest. A retrospective study. Eur J Paediatr Dent 20:111115. https://doi.org/10.23804/ejpd.2019.20.02.05

20. Oldin A, Lundgren J, Nilsson M, Noren JG, Robertson A (2015) Traumatic dental injuries among children aged 0-17 years in the BITA study - a longitudinal Swedish multicenter study. Dent Traumatol 31:9-17. https://doi.org/10.1111/edt.12125

21. Traebert J, Almeida IC, Marcenes W (2003) Etiology of traumatic dental injuries in 11 to 13 -year-old schoolchildren. Oral Health Prev Dent 1:317-323

22. Bonini GC, Bonecker M, Braga MM, Mendes FM (2012) Combined effect of anterior malocclusion and inadequate lip coverage on dental trauma in primary teeth. Dent Traumatol 28:437-440. https://doi.org/10.1111/j.1600-9657.2012.01117.x

23. Wedl JS, Schoder V, Friedrich RE (2004) Tooth eruption times of permanent teeth in male and female adolescents in Niedersachsen. Arch Kriminol 213:84-91

24. Lakshmappa A, Guledgud MV, Patil K (2011) Eruption times and patterns of permanent teeth in school children of India. Indian J Dent Res 22:755-763. https://doi.org/10.4103/0970-9290.94568

25. Parner ET, Heidmann JM, Vaeth M, Poulsen S (2001) A longitudinal study of time trends in the eruption of permanent teeth in Danish children. Arch Oral Biol 46:425-431. https://doi.org/10. 1016/s0003-9969(01)00002-4

26. Odersjo ML, Robertson A, Koch G (2018) Incidence of dental traumatic injuries in children 0-4 years of age: a prospective study based on parental reporting. Eur Arch Paediatr Dent 19:107-111. https://doi.org/10.1007/s40368-018-0334-z

27. Zaitoun H, North S, Lee S, Albadri S, McDonnell ST and Rodd HD (2010) Initial management of paediatric dento-alveolar trauma in the permanent dentition: a multi-centre evaluation. Br Dent J 208:E11; discussion 254-5. doi: https://doi.org/10.1038/sj.bdj.2010.254

28. Piovesan C, Guedes RS, Casagrande L, Ardenghi TM (2012) Socioeconomic and clinical factors associated with traumatic dental injuries in Brazilian preschool children. Braz Oral Res 26:464-470. https://doi.org/10.1590/s1806-83242012000500014

29. de Amorim LF, da Costa LR, Estrela C (2011) Retrospective study of traumatic dental injuries in primary teeth in a Brazilian specialized pediatric practice. Dent Traumatol 27:368-373. https://doi. org/10.1111/j.1600-9657.2011.01011.x

30. Born CD, Jackson TH, Koroluk LD, Divaris K (2019) Traumatic dental injuries in preschool-age children: prevalence and risk factors. Clin Exp Dent Res 5:151-159. https://doi.org/10.1002/ cre2.165

31. Borzabadi-Farahani A, Gross J, Sanchez-Lara PA, Yen SL (2013) An unusual accessory mandible and a submucosal cleft palate-a case report and review of the literature. Cleft Palate Craniofac $\mathbf{J}$ 50:369-375. https://doi.org/10.1597/11-032

32. ElKarmi RF, Hamdan MA, Rajab LD, Abu-Ghazaleh SB, Sonbol HN (2015) Prevalence of traumatic dental injuries and associated factors among preschool children in Amman, Jordan. Dent Traumatol 31:487-492. https://doi.org/10.1111/edt.12183

33. Goettems ML, Azevedo MS, Correa MB, Costa CT, Wendt FP, Schuch HS, Bonow ML, Romano AR, Torriani DD (2012) Dental 
trauma occurrence and occlusal characteristics in Brazilian preschool children. Pediatr Dent 34:104-107

34. Mendoza-Mendoza A, Iglesias-Linares A, Yanez-Vico RM, Abalos-Labruzzi C (2015) Prevalence and complications of trauma to the primary dentition in a subpopulation of Spanish children in southern Europe. Dent Traumatol 31:144-149. https://doi.org/10. 1111/edt.12147

35. Feliciano KM, de Franca CA, Jr. (2006) A systematic review of the diagnostic classifications of traumatic dental injuries. Dent Traumatol 22:71-76. https://doi.org/10.1111/j.1600-9657.2006. 00342.x
36. Ilia E, Metcalfe K, Heffernan M (2014) Prevalence of dental trauma and use of mouthguards in rugby union players. Aust Dent J 59:473-481. https://doi.org/10.1111/adj.12223

37. Green JI (2017) The role of mouthguards in preventing and reducing sports-related trauma. Prim Dent J 6:27-34. https://doi.org/10. $1308 / 205016817821281738$

Publisher's Note Springer Nature remains neutral with regard to jurisdictional claims in published maps and institutional affiliations. 